\title{
¿EL VATICANO II AL SERVICIO DE LA \\ INTERCULTURALIDAD Y DE UN GIRO DECOLONIAL? UN PROYECTO INTERCONTINENTAL EN DESARROLLO
}

\author{
Vatican II at the Service of Interculturality and a Decolonial Turn? An Inter- \\ continental Project in Development
}

Carlos Schickendantz *

RESUMEN: Se encuentra en desarrollo un proyecto internacional conformado por grupos de investigación en los cinco continentes en torno al Vaticano II y sus procesos de recepción que culminará con la publicación de doce volúmenes. En debates recientes emergen cuestiones caracterizadas por las categorías de subalternidad, colonialidad, decolonialidad, geopolítica del conocimiento que suscita la pregunta acerca del significado de poner en el centro de un proyecto intercontinental al Vaticano II. En esta contribución se presta atención a la objeción que proviene de estas perspectivas y a las interpretaciones del Concilio que favorecen su lectura en clave de interculturalidad. Se ofrecen, también, consideraciones sobre el significado del Vaticano II en el marco del proceso continental de estas décadas que manifiestan una gran sintonía con varias de las demandas explicitadas en los planteos provenientes del llamado giro decolonial. El Concilio pertenece al discurso liberador y emancipador en América Latina y el Caribe

PALA BRAS-CLAVE: Concilio. Descolonización epistemológica. Geopolítica del conocimiento.

A BSTRACT: A group of researchers from five continents are working on producing a twelve volume series on the Second Vatican Council and its global processes of reception. As debates emerge surrounding issues of subalternity, colonialism, decolonialism, and the geopolitics of knowledge, a new set of questions has been raised on the significance of such a project that places Vatican II at the center of

\footnotetext{
* Universidad Alberto Hurtado, Santiago, Chile.
} 
international efforts. This paper pays special attention to the difficulties raised by these questions and to interpretations of the Council in favour of interculturality. Further consideration will be given to the role of Vatican II in the historical development of the continent over the course of the past decades as well as to the Council's acquiescence to many demands of decolonization. Indeed, in both Latin America and the Caribbean, the Council took up discourses of liberation and emancipation.

KEYWORDS: Council. Epistemological Decolonization. Geopolitics of Knowledge.

\section{Introducción $n^{1}$}

Con la conmemoración de los 50 años del Concilio Vaticano II se han realizado en estos años congresos, proyectos de investigación y nuevas publicaciones que, desde distintos puntos de vista, han ofrecido la oportunidad para profundizar en este acontecimiento mayor de la historia de la Iglesia católica en el siglo XX -“un evento de proporciones inimaginables, convirtiéndose en la asamblea consultiva / deliberativa más amplia jamás reunida, incluso en el ámbito de la política civil" (BEOZZO; LUZ MARQUES, 2011, p. 987) - y sus importantes procesos de recepción en toda la geografía de la Iglesia. El listado es casi inabarcable, pero algunos eventos pueden destacarse. En octubre de 2012 se llevó a cabo un Congreso Continental de Teología en São Leopoldo/RS, Brasil conmemorando dos eventos, los 50 años de la inauguración del Vaticano II y los 40 años de la Teología de la liberación (CONGRESO CONTINENTAL DE TEOLOGÍA, 2013). En febrero de 2013 se concretó un seminario internacional en Bangalore, India (KOCHUTHARA, 2014-2015). En setiembre de 2013 con el título de "The legacy of Vatican II" se realizó un seminario internacional en Boston, USA (Faggioli; Vicini, 2015). Entre los años 2013 y 2015 se desarrolló un proyecto internacional patrocinado por la Federación Internacional de Universidades Católicas (FIUC) que se extendió por varios años, tuvo su reunión principal en París en abril de 2015 y culminó con una publicación en varios idiomas (LAMBERIGTS et al., 2015). En setiembre de 2015 tuvo lugar un congreso en Buenos Aires (GALLI, 2015), y a comienzos de diciembre de ese año hubo otro encuentro importante en Múnich, con participantes casi en su totalidad de lengua alemana (BÖTTIGHEIMER; DAUSNER, 2016).

Además de las publicaciones con ocasión de esos eventos, han aparecido también en estos años obras remarcables. ${ }^{2}$ En 2014, en el marco de una iniciativa de la Associazione teológica italiana, se inició la publicación de

\footnotetext{
${ }^{1}$ Este texto se enmarca en el proyecto de investigación Fondecyt № 1190556.

${ }^{2}$ Un panorama general de publicaciones de estos años ofrece FAGGIOLI (2019a).
} 
un nuevo comentario a todos los documentos del Concilio Vaticano II en lengua italiana. La edición general está a cargo de Serena Noceti y Roberto Repole y cuenta con la participación de más de 30 especialistas, en su gran mayoría pertenecientes a ese espacio lingüístico. Están previstos nueve volúmenes, siete han sido publicados ya al mes de junio de 2020. ${ }^{3}$ En 2015 se ha publicado en São Paulo un diccionario sobre el Concilio muy significativo para la región, con mucha información valiosa, en sus varios anexos, por ejemplo, para el trabajo sobre el Vaticano II (Decio Passos; Lopes Sanchez, 2015); otro con características diferentes en España también (VILLAR, 2015). En Latinoamérica y el Caribe la proximidad con la celebración de los 50 años de la Conferencia de Medellín, en 2018, ofreció también la oportunidad para que la obra conciliar estuviera muy presente en los más diversos eventos y publicaciones. Otros importantes trabajos han sido ya publicados o están próximos a aparecer. Por ejemplo, por una parte, la extensa y muy buena obra del autor australiano Ormond Rush (RUSH, 2019), por otra, un volumen editado por Richard Gaillardetz, con renombrados colegas del ambiente norteamericano, en la colección The Cambridge Companion (GAILLARDETZ, 2020). ${ }^{4}$

\section{Un proyecto de investigación en desarrollo}

En ese marco, una obra de la década anterior es muy relevante. Con autores casi exclusivamente de lengua alemana, se llevó a cabo un proyecto que concluyó en 2005 con un nuevo comentario a toda la obra conciliar en cinco volúmenes (Hünermann; Hilberath, 2004-2005). Por razones de acceso lingüístico, no tuvo la repercusión deseada en otras regiones geográficas. En 2016 surgió la idea de actualizar esa obra, buscando al mismo tiempo una mayor internacionalización. Después de varias reuniones con teólogos y teólogas de diferentes continentes se puso en marcha un proyecto muy ambicioso, que ahora está en desarrollo. ${ }^{5}$ La obra concluida incluirá doce volúmenes en versiones inglesa y alemana, que serán de libre acceso en una versión online.

\footnotetext{
${ }^{3}$ Cf. el primero volumen (GIRARDI; GRILLO; VIGANÒ, 2014).

${ }^{4}$ En 2021 se publicará un trabajo aún más detallado e internacional (CLIFFORD; FAGGIOLI, 2021).

${ }^{5}$ Cf. VATICAN II. Legacy and mandate. Disponible en: <https://www.pthv.de/forschung/ projekte-theologie/uebersicht-projekte-theologie/projekte-in-der-historischen-theologie/vatican-ii-legacy-and-mandate/>. Acceso en: 20 mayo 2020. El comité directivo del proyecto en Alemania incluye a Joachim Schmiedl (Vallendar), Peter Hünermann (Tübingen), Margit Eckholt (Osnabrück), Klaus Vellguth (Vallendar). Los coordinadores/as continentales: Nontando Hadebe (South Africa), Catherine Clifford (Ottawa), Massimo Faggioli (Philadelphia), Ormond Rush (Brisbane), Shaji George Kochuthara (Bangalore), Carlos Schickendantz (Santiago de Chile).
} 
El proyecto en ejecución tiene dos fases diversas, pero íntimamente relacionadas (Faggioli, 2019b; ECKHOLT, 2020). Primero, un trabajo en cada uno de los continentes con grupos de investigación conformados por unas 20 personas aproximadamente en cada región (África, Asia, Europa, Latinoamérica y el Caribe, Norteamérica y Oceanía). En un proceso de unos tres años, ya iniciado a fines de 2018, cada grupo continental está elaborando un volumen que contiene estudios sobre la situación regional antes del Vaticano II en orden a destacar mejor las transformaciones producidas después, los aportes hechos al mismo Concilio y, finalmente, los procesos de recepción de estas décadas. Este último punto incluye, también, un estado de la cuestión en los diferentes asuntos de la vida de la Iglesia y de la teología. La recepción pertenece al proceso conciliar; al final las mismas comunidades cristianas como verdaderas agentes de la recepción deciden la relevancia histórica de un evento conciliar, más allá de su validez jurídica o de su recepción oficial por parte del magisterio. ${ }^{6}$ Esa primera parte del proyecto concluirá, entonces, con cinco volúmenes; uno por cada continente.

Esta tarea continental ya en desarrollo es muy interesante, pero no es sencilla por varios motivos. Por ejemplo, salvo en Europa, en los demás continentes no existe un trabajo sistemático ya realizado sobre los aportes de las diferentes regiones al debate conciliar de entonces. ${ }^{7}$ Hay aquí una tarea de estudio de fuentes que requiere tiempo. Por otra parte, en las distintas regiones geográficas, también en América Latina y el Caribe, somos cada vez más conscientes de la diversidad cultural, incluso al interior de nuestros mismos países, que complejiza la comprensión e interpretación. El desafío del Asia, por ejemplo, con realidades tan diversas en países como Corea del Sur, Japón, China, India, etc. ofrece un panorama casi inabarcable. Y con diferencias, naturalmente, esto se verifica de forma análoga en cada uno de los continentes. Pero no obstante todas las dificultades y desafíos que este escenario ofrece, las ventajas de estas amplias perspectivas se perciben inmediatamente. Para pensar en profundidad los temas de hoy es necesaria esa conciencia global que se alimenta del compartir tiempo juntos, escuchar pacientemente las historias de los otros y de las otras, comparando y diferenciando con las historias y los problemas de la propia región. La interculturalidad

\footnotetext{
${ }^{6}$ La importante categoría de recepción, clave en este proyecto, ha sido enriquecida en estas décadas, gracias también a los aportes filosóficos hermenéuticos. "A lo largo de este proceso de recepción creativa, lo que el receptor encuentra relevante en la visión conciliar puede ser impredecible, dependiendo de su contexto. Una idea de la hermenéutica literaria ha demostrado ser cierta sobre la recepción del Concilio. La recepción implica selección. Un receptor puede poner ciertos elementos en la visión en primer plano como más importantes que otros para un contexto particular" (RUSH, 2020, p. 108).

${ }^{7}$ El trabajo de José Oscar Beozzo es ejemplar, pero constituye casi una excepción en el continente (BEOZZO, 2005; BEOZZO; LUZ MARQUES, 2011). Existen trabajos más recientes en Argentina y Chile (ARENAS; ARANDA, 2014; LIBERTI, 2017).
} 
"no es solo un tema teórico sino primordialmente una experiencia" (Fornet-Betancourt, 2009, p. 640).

Ese interesante trabajo en cada continente sirve de base para la segunda fase del proyecto que es la confección de los nuevos comentarios a los dieciséis documentos conciliares. A partir de un borrador puesto en una plataforma web, cinco personas, una por cada continente, ayudados por un coordinador/a, escribirán esos textos que, de forma análoga al trabajo continental previo, también incluirán información sobre todo el proceso conciliar (fase previa e historia de la redacción de cada documento), además de un comentario a cada número particular, seguido, en una tercera parte, por la historia de la recepción de las temáticas de cada documento. Es una obra ambiciosa y, en un sentido, con una metodología no ensayada antes: escribir un comentario conciliar "a múltiples manos" pertenecientes a cada uno de los continentes. En esta tarea están comprometidas unas noventa personas de los más variados países. Este proceso está siendo acompañado por workshops anuales en cada continente y por una reunión general, también anual, que permite coordinar y poner en diálogo múltiples teólogos y teólogas de distintos lugares.

A los diez volúmenes descritos -los cinco continentales y los cinco dedicados a los comentarios conciliares- se añade un volumen introductorio, ya en elaboración, que desea poner de relieve, particularmente, la hermenéutica intercultural que ilumina el camino, y un volumen conclusivo, que mostrará una visión de conjunto y una referencia a los principales frutos conseguidos a lo largo de todo el proceso. No solo el resultado previsto aparece como relevante, los doce volúmenes, sino todo el desarrollo de un diálogo global sistemático.

El proyecto puede ser visto, también, como señal de un nuevo momento de conciencia cultural. Por una parte, no puede desconocerse que con el papado de un obispo latinoamericano

la reflexión acerca de una iglesia mundial ha crecido significativamente. El catolicismo se dice cada vez más en múltiples lenguas y culturas. En ese marco, el Vaticano II puede funcionar como una plataforma común global en el que están contenidas, a veces en germen, las líneas maestras para el tiempo que viene, el tercer milenio del cristianismo.

Pero también desde este punto de vista se presenta la pregunta acerca de la oportunidad de un trabajo intercontinental centrado en el Concilio y su recepción posterior. Al inicio de su obra, Le concile Vatican II. Quel avenir?, Christoph Theobald manifiesta dos preocupaciones en relación al Vaticano II: por una parte, la distancia temporal y, sobre todo, cultural con la época del Concilio, que cuestiona la posibilidad de acudir a él como una referencia común y, por otra, la forma adecuada de enfrentar una situación cultural inédita que, en el caso europeo, él califica como de "exculturación" de la 
fe. En ese marco, su interés radica en poner de relieve la actualidad y, sobre todo, el significado que el Concilio tiene para el futuro de la vida de la Iglesia (THEOBALD, 2015A). ${ }^{8}$

En debates recientes en diversas ciencias sociales y de humanidades emerge otra cuestión, análoga, no idéntica, que suscita la pregunta acerca del significado de poner en el centro de un proyecto intercontinental al Vaticano II. Me refiero a los múltiples y diversos trabajos que, animados por los Cultural Studies y los Subaltern Studies surgidos en lengua inglesa, han obtenido un creciente desarrollo en América Latina y el Caribe caracterizados por las categorías de subalternidad, colonialidad, poscolonialismo, decolonialidad, geopolítica del conocimiento, etc. No es necesario compartir todas sus interpretaciones históricas o sus análisis teóricos, incluso debido a su gran diversidad, para reconocer que en estos posicionamientos residen, al menos, advertencias y críticas bien fundadas (SUESS, 2013; MELLA, 2016; ALBUQUERQUE, 2019).

En las páginas que siguen refiero a una objeción general que se formula a partir de estas perspectivas y que, en particular, suscitan la cuestión acerca de la naturaleza intercultural del Concilio, luego, ofrezco consideraciones sobre el significado del Vaticano II en el marco del proceso histórico-eclesial latinoamericano y caribeño de estas décadas que manifiestan una gran sintonía con varias de las demandas explicitadas en los planteos provenientes del llamado giro decolonial.

\section{Acerca de la descolonización epistemológica en el continente}

En un texto reciente el filósofo Enrique Dussel ha renovado sus planteos acerca de la descolonización epistemológica de la teología (DUSSEL, 2018). El autor recuerda al comienzo el hecho de que el tema de la "descoloniza-

\footnotetext{
${ }^{8}$ La conciencia de la distancia y el punto de partida a partir de las cuestiones actuales parece clave en orden a percibir la relevancia de la obra conciliar. "En 1985, Hermann Joseph Pottmeyer pidió una nueva generación de comentarios sobre los textos conciliares. ¿Qué debemos entender por el término 'una nueva generación de comentarios'? En mi opinión, podemos responder esto solo si, comenzando con las preguntas de hoy, estamos de acuerdo en hacer un nuevo interrogatorio a los documentos conciliares, considerados no como una colección de pronunciamientos y conclusiones, sino más bien como la acción de una asamblea que comprendió estas preguntas de una manera original, trabajaron en ellas de acuerdo con un método apropiado, y así lograron producir un discurso que sorprendió a una generación y que puede cautivar a una nueva generación hoy. En ese momento, podemos captar la 'acción' de los Padres conciliares y, con ellos, encontrar nuevamente ese estado de efervescencia que los llevó a pensar de manera fresca las preguntas que enfrentó la Iglesia durante la segunda mitad del siglo XIX y la primera mitad del XX, logrando hablar un nuevo idioma sobre las diversas preguntas que nos preocupan hoy" (ROUTHIER, 2013, P. 554).
} 
ción epistemológica" se originó en un grupo de filósofos, historiadores y científicos sociales latinoamericanos y latinos en Estados Unidos. Se trata de la elaboración de una problemática que se inició con trabajos críticos en los llamados Cultural Studies en Inglaterra, los Subaltern Studies promovidos por historiadores de la India y posiciones posmodernas, sobre todo, en Europa y Estados Unidos. También recuerda que dicha descolonización es un desarrollo ulterior de la teoría de la dependencia (década de 1960), la crítica del capitalismo centralizado en relación con su periferia, la teología de la liberación, el tema de la raza, el feminismo y el género, así como de los pueblos originarios. Se estructura en torno a lo que se ha llamado la "colonialidad del poder", propuesta por el sociólogo peruano Aníbal Quijano, y "transmodernidad", que surgió en el horizonte de la teología de la liberación en el cual se sitúan varios filósofos latinoamericanos y latinos, entre los que se cuenta el mismo Dussel. En el marco de esa compleja trama, a la que deberían añadirse muchos matices y nombres, emerge la temática de la descolonización epistemológica.

Al final de su texto Dussel formula algunas afirmaciones que resultan pertinentes considerar aquí. Destaca dos aspectos: el primero, el hecho de que, a su juicio, "incluso los grandes teólogos del siglo XX, como Henri de Lubac, Karl Rahner, Yves Congar y Jürgen Moltmann, eran, y no podían no ser, eurocéntricos. Renovaron creativamente las teologías europeas, pero fueron incapaces de situar su subjetividad (incluso su corporalidad) dentro del 'espacio colonial', en el mundo del otro colonizado". En segundo lugar, incluye una significativa frase sobre el Concilio: "el Vaticano II 'arregló' o resolvió la distancia de la Iglesia con la Ilustración a través de un ecumenismo intraeuropeo, pero no con el mundo colonial" (DUSSEL, 2018, p. 60-61). En ese contexto Dussel, no sin expresiones irónicas, realiza una crítica dirigida a académicos del sur global, a "los estudiantes latinoamericanos, africanos y asiáticos" a quienes se enseñó "la mejor teología europea". Describiendo distintas estrategias y caminos seguidos en sus diversas biografías, Dussel advierte de un "lavado de cerebro", conforme al cual, los "estudiantes del sur se transformaron en intelectuales eurocéntricos" y "volviendo a sus espacios culturales de origen, se encontraron en un mundo colonizado, alienados de su propia cultura y de su propio imaginario religioso popular." El autor rescata de ese diagnóstico a "muy pocos casos" pertenecientes a la teología de la liberación latinoamericana que pensaron "con sus propias cabezas" aprovechando elementos de "las ciencias sociales críticas que la teología eurocéntrica nunca había usado", como, por ejemplo, enumera al marxismo, al psicoanálisis, a una historia no eurocéntrica, etc. Esta nueva teología, argumenta Dussel, "fue perseguida, no tanto por su contenido sino por su intento de pensar desde fuera de Europa y contra la Europa moderna, capitalista, metropolitana, eurocéntrica, machista y racista que había confundido su propia particularidad con un reclamo de universalidad" (DUSSEL, 2018, p. 62). En la evaluación final Dussel señala que la descolonización epistemológica de la teología es "un hecho 
que comenzó durante la segunda mitad del siglo $X X$, pero que durará todo el siglo XXI". En ese marco advierte, además, que dicha descolonización "comienza situándonos en un nuevo espacio desde el cual, como locus enuntiationis y hermenéutica original, será necesario rehacer la teología como un todo" (DUSSEL, 2018, p. 62; ARCE-VALENTIN, 2017).

En realidad, como muestran múltiples autores, la crítica a estas limitaciones hermenéuticas no han sido exclusivamente dirigida a las teologías, sino que ha sido direccionada también a otros campos del saber y de la academia, e incluso no solo en relación a un arco ideológico más conservador. Precisamente, como ha destacado el filósofo salvadoreño Juan Blanco, los "estudios culturales surgieron como una estrategia teórica, metodológica y epistemológica alternativa a la ceguera de las disciplinas canónicas y de las ideológicas esencialistas de izquierda. La cultura de masas, las reivindicaciones de los grupos excluidos (mujeres, homosexuales, indígenas, negros, etc.) estimulaban la creación de nuevas y más incluyentes formas académicas para la comprensión de los fenómenos socioculturales emergentes" (BLANCO, 2009, p. 86; LANDER, 2000; CASTRO-GOMEZ, 2002). La ruptura con esta a-topia del saber es lo que llevó a Walter Mignolo, autor clave en estas perspectivas, a reconocer la necesidad de hacer visible lo que llama la "geopolítica del conocimiento". "Insisto en la localización... puesto que sabemos ya desde hace tiempo que todo pensamiento está localizado, pero, a pesar de esto, hay una tendencia general a entender el pensamiento construido a partir de la historia y experiencia europea como si estuviera des-localizado." (MIGNOLO, 2007, p. 33). La ceguera ante la situación particular del saber es la que hizo posible la autocomprensión hegemónica de Occidente, argumentan, y, por tanto, es la insistencia en la importancia de la propia tradición intelectual situada, es decir, producto de un determinado lugar de enunciación, un eje particular sostenido a lo largo de la producción teórica de estos autores y autoras (BLANCO, 2009, p. 112).

Esta "ceguera epistémica", compartida por los más diferentes liderazgos personales sociales, políticos y eclesiales y por ciencias sociales y humanas, es posible verificarla en múltiples ejemplos de alteridades negadas en las narrativas del continente. Uno de los más relevantes refiere a la que se considera la minoría más invisibilizada de América Latina: la población afrodescendiente llegada, en su mayoría, con el comercio de esclavos entre los siglos XVII y XIX. Aunque las cifras de su población, muy heterogénea, carecen de la precisión deseada, se calcula que representan más del $20 \%$ de la población del continente, con una fuerte concentración en Brasil, más del 45\% de su población, y en Cuba (35\%). En 2015 se estiman un total de 130 millones de afrodescendientes (CEPAL, 2017, p. 51). Múltiples indicadores señalan la creciente conciencia de la complejidad de este mundo fuertemente marcado por el racismo, la pobreza y la marginalidad. Afortunadamente, algo está cambiando en la región 
como muestran diversos informes internacionales. Una de las primeras señales de cambio fue la creciente inclusión de variables etno-raciales en las estadísticas nacionales, también la adopción de una variedad de políticas de acción afirmativa, como cuotas reservadas en el mercado laboral y en instituciones educativas, campañas de concientización, legislación antirracista y el surgimiento de una clase política de afrodescendientes (FREIRE et al., 2018). Reformas en las constituciones políticas nacionales, surgimiento de organizaciones sociales intermedias, incorporación de estas temáticas en las academias universitarias son otras iniciativas relevantes de las últimas décadas. Los diversos mecanismos utilizados para la invisibilización como, por ejemplo, las narrativas nacionales dominantes o las formas de clasificación racial, están siendo estudiados y denunciados de manera creciente (FRIGERIO, 2008). En ese marco, a inicios de la década de 2000 en una reunión patrocinada por Naciones Unidas se formularon estas frases que testimonian con claridad un nuevo momento en la auto conciencia continental: "la identidad de las Américas no puede disociarse de su carácter multirracial, pluriétnico, multicultural, multilinguístico y pluralista; diversidad que constituye un aporte a la convivencia humana y a la construcción de culturas de respeto mutuo y de sistemas políticos democráticos" (LECHINI, 2008, p. 14; SUSIN, 2001).

\section{3 ¿El Vaticano II al servicio de la interculturalidad y de un giro decolonial?}

El planteo de Dussel referido, análogo al de otros autores latinoamericanos que trabajan desde la perspectiva del giro decolonial, requeriría un análisis detallado de cada una de las afirmaciones que se proponen, pero no puede negarse que sacan a la luz una cuestión clave del debate continental de estas últimas décadas. Interesa aquí, particularmente, su referencia al Vaticano II: “'arregló' o resolvió la distancia de la Iglesia con la Ilustración a través de un ecumenismo intraeuropeo, pero no con el mundo colonial" (DUSSEL, 2018, p. 61). Con esta afirmación se plantea la pregunta acerca del sentido que tiene situar al Vaticano II como centro de un proyecto de trabajo internacional precisamente desde una perspectiva intercultural y de futuro. Como he expresado, es una pregunta análoga, aunque no idéntica, a la formulada por C. Theobald en su obra francesa de 2015. ${ }^{9}$ En el caso del planteo formulado por Dussel la dificultad reside en la desatención

\footnotetext{
${ }^{9}$ También en el caso de América Latina y El Caribe la distancia temporal y cultural con la época del Concilio es relevante. Algunos nuevos desafíos, junto a otros persistentes como la pobreza y la inequidad, destaca bien J. O. Beozzo: el empeoramiento de la crisis medioambiental, el pluralismo religioso, la pentecostalización del cristianismo, la mediatización del mensaje religioso, la masificación y el anonimato del mundo urbano (BEOZZO, 2012).
} 
por parte del Concilio a un asunto clave actual, que en buena medida se condensa en la exigencia de un giro decolonial en todos los niveles del pensamiento y de la acción. Por su situación temporal y su localización geográfico-eclesial el Vaticano II, muy visibles en la agenda principal y en la participación activa de sus más relevantes actores (belgas, franceses, alemanes, italianos, etc.), parece tener una limitación radical.

¿Qué puede decirse al respecto? Las comunidades eclesiales y, en ellas, teólogos y teólogas del continente latinoamericano y caribeño han sido bien conscientes del carácter predominantemente europeo de los debates conciliares. La limitación más evidente la han advertido, quizás, en el escaso éxito que tuvo la temática de la "Iglesia de los pobres" en la agenda conciliar. Pero lejos de juzgar negativamente al Vaticano II, han ofrecido a lo largo de las décadas en las más diversas publicaciones y eventos un juicio positivo, abrumadoramente mayoritario, considerando al Concilio un verdadero Pentecostés, siempre leído juntamente con las intenciones pastorales de Juan XXIII, la significativa encíclica Populorum progressio (1967), calificada "algo así como la Gaudium et spes del tercer mundo" (GUTIÉRREZ, 2018, p. 86) y, sobre todo, el evento mayor del catolicismo del siglo XX en el continente: la Conferencia de Medellín (1968). Esta evaluación positiva es fácilmente verificable no solo en las teologías de la liberación iniciales de la década del setenta (GUTIÉRREZ, 1971, p. 23-24, 55, 167, 319-320, 351-352; BOFF, 1988; LIBANIO, 1995), sino también en las posteriores corrientes teológicas feministas (AZCUY, 2015), indígenas (TOMICHÁ, 2013, p. 1779) y afroamericanas (RODRÍGUES DA SILVA, 2013, p. 1770-1771).

A partir de la observación de Dussel y de la experiencia de la recepción conciliar en el continente parece importante destacar, por una parte, que la interpretación del Concilio que se asume resulta casi decisiva y, por otra, que el proceso histórico de las comunidades eclesiales del continente en el posconcilio ha producido, también gracias al Vaticano II, frutos valiosos precisamente en la línea fundamental que demandan las corrientes pertenecientes a los planteos decoloniales citados. Me detengo en estos dos aspectos.

\section{Un principio conciliar verificado en favor de la interculturalidad: la pastoralidad}

Las reflexiones anteriores pueden ser analizadas desde distintos puntos de vista a partir de la obra conciliar. El debate permite apreciar, aún más, la relevancia de la interpretación fundamental de K. Rahner. No obstante sus limitaciones, se trata de una de las lecturas globales y epocales del Concilio con gran consenso internacional, incluso en nuestra región (GUTIÉRREZ, 
1987, p. 214; NOEMI, 1998, p. 22, 55). El giro decolonial, más allá de la terminología, es allí central en la argumentación. ${ }^{10}$ Otra perspectiva global clave, de las más relevantes en el contexto teológico actual, está dada por la comprensión de la pastoralidad en la obra de C. Theobald. A partir de ella es posible reconocer e interpretar líneas fundamentales en el proceso posconciliar del continente latinoamericano y caribeño.

\subsection{El concepto de pastoralidad según Christoph Theobald}

El concepto de pastoralidad que se traduce en un modus procedendi codificado en la obra conciliar, especialmente en Ad gentes 22 y Gaudium et spes 44, le parece decisivo. " "Supone una relación constitutiva entre la evangelización y sus destinatarios, y consiste en conjugar una hermenéutica del Evangelio y una hermenéutica de las lenguas y las culturas, susceptibles de recibir la Buena Noticia de Cristo" (THEOBALD, 2018a, p. 461; 2015b, p. 28). Esta forma de proceder implica una "escucha estereofónica" y varias prácticas. Por una parte, la escucha eclesial de la Palabra de Dios que se concreta, especialmente, mediante la práctica de la lectura de la Biblia (DV), por otra, mediante la lectura de los signos de los tiempos (GS). La escucha de la voz de Dios solo es posible en una escucha estereofónica de "las múltiples voces de nuestro tiempo" (GS 44) y, añade, en sus resonancias en la conciencia (THEOBALD, 2016, p. 43). Estas dos lecturas - o escuchas - no pueden separarse, sino ambas fracasan (interpretación de la Biblia e interpretación del momento presente). "El punto nodal de la pastoralidad es la relación no explicitada entre la Constitución sobre la revelación Dei Verbum y la Constitución pastoral Gaudium et spes" (THEOBALD, 2018b, p. 35). Según su análisis, precisamente, "una de las mayores dificultades en la recepción del Vaticano II" es la "ausencia de este vínculo" en esta doble práctica: la del discernimiento de los signos de los tiempos y la de una lectura actual de la Biblia (THEOBALD, 2009, p. 833).

Un paso más. Por otra parte, esta doble tarea hermenéutica intrínsecamente vinculada no puede concretarse si esas prácticas no están fundadas en una capacidad de escucha y aprendizaje, si se carece de una iniciación espiritual que da acceso a la interioridad y, últimamente, al coloquio personal indi-

10 “Las cosas están por tanto así: o la Iglesia ve y reconoce estas diferencias esenciales de las otras culturas, en el seno de las cuales debe llegar a ser Iglesia mundial, y de ese reconocimiento saca las consecuencias necesarias con audacia paulina, o bien permanece como una Iglesia occidental, a fin de cuentas, traicionando de esta manera el sentido que ha tenido el Vaticano II." (RAHNER, 1980, p. 298).

${ }^{11}$ En el análisis de C. Theobald "la última palabra del Concilio sobre el problema hermenéutico" es el texto de AG 22, además de la importancia de la formulación en GS 44; implica más que una adaptación o acomodación que representaría "una cierta exterioridad o una relación instrumental entre verdad y contexto histórico" (2009, p. 314). En este punto (4.1.) aprovecho con libertad y algunas modificaciones mis propias consideraciones sobre Theobald (SCHICKENDANTZ, 2018b, p. 91-93). 
vidual y litúrgico con Dios (SC). Estas prácticas acontecen en la ilimitada pluralidad de las experiencias contextualizadas de sus protagonistas y destinatarios. Implican, además, una manera de entendernos mutuamente, una búsqueda común de la verdad (UR, NA), con estrategias no autoritarias basadas en el diálogo y la argumentación (DH), efectuadas y concretadas en una manera conciliar o sinodal (LG, OE, CD, PO, PC, AA).

Este modus procedendi o también llamado por él "gramática generativa" -la "doble escucha" y las varias "prácticas"- origina un "proceso eclesio-genético", una "fundación" de la Iglesia "desde abajo", tal como en el Concilio se describe para las nuevas iglesias de misión (AG). Theobald advierte que la perspectiva fundadora de las comunidades primitivas no ejerce una función estructurante en Lumen gentium. De allí su invitación a interpretar la visión global de Lumen gentium a partir de la perspectiva eclesio-genética del documento sobre las misiones (THEOBALD, 2015a, p. 167, 212, 214, 208, 209). A su juicio, dicha "gramática inventada por el Concilio" constituye una "manera de formar hoy existencias cristianas y eclesiales en nuestra propia situación cultural" (THEOBALD, 2015a, p. 11, 160; 2015b, p. 32-34). Se trata de un "proceso eclesio-genético" a la búsqueda de una figura de Iglesia portadora de futuro.

En ese marco de ideas se entiende su comprensión del concepto de pastoralidad, que se formula de maneras diversas, aunque próximas, en distintos contextos temáticos: "es una manera de designar esta nueva complejidad acerca de una escucha contextualizada de la Palabra de Dios en el corazón de un proceso histórico de aprendizaje, que de algún modo se ha cristalizado durante el Concilio, para ser legado a la posteridad" (THEOBALD, 2015a, p. 160). Es claro para Theobald que en este "modus procedendi pastoral" se encuentra la enseñanza más decisiva y cargada de futuro del Vaticano II (THEOBALD, 2018b, p. 34-44).

\subsection{El proceso continental a la luz de esa interpretación}

El análisis del teólogo de París invita a apreciar aún más el proceso de recepción latinoamericano y caribeño del Vaticano II que ha tenido un punto central, precisamente, en relación a esta forma de proponer la pastoralidad del Concilio y sus variados elementos.

En primer término, la Biblia en las manos de la gente. Constituye, en cierto modo, el principal hecho de recepción del Concilio según José Oscar Beozzo. "La herencia del Concilio encontró su expresión más significativa y creativa en la lectura popular de la Biblia, una amplia apropiación comunitaria de la Palabra de Dios que alimentó el camino de las comunidades eclesiales de base y de las pastorales sociales a lo largo de estos años, con gran protagonismo de los laicos, de modo particular de las mujeres" (BEOZZO, 2012, p. 442). En palabras de Ronaldo Muñoz: “Es tal vez uno 
de los cambios más notables de la Iglesia católica en América Latina el que se convoque a comunidades y se coloque la Biblia en manos de los pobres. Eso es absolutamente inédito" (VENEGAS; MORENO, 2010, p. 92). Estas afirmaciones encuentran un consenso importante por parte de muchos autores/as (RICHARD, 2007, p. 11; MESTERS; OROFINO, 2015).

En segundo lugar, la práctica teológico-pastoral de interpretación de los signos de los tiempos. Se trata de una experiencia fundamental que revela que, probablemente, Gaudium et spes representó el texto conciliar de mayor impacto en la vida de las iglesias del continente (CODINA, 2013, p. 84; NOEMI, 1998, p. 19-20; Schickendantz, 2017; Schickendantz, 2018a). Y esta doble escucha y lectura "estereofónica" inseparable -interpretación de la Biblia e interpretación del momento presente- se concretó en un círculo hermenéutico continuo, aunque este aspecto no siempre haya sido suficientemente explicitado y metodológicamente fundado. En ese marco, la localización, el contexto socio-histórico, adquirió un nuevo significado. El teólogo chileno Juan Noemi ha caracterizado justamente la nueva situación: "Con anterioridad al Vaticano II predomina un ejercicio teológico para el cual el contexto espacial y temporal constituye una exterioridad, un accidente que no es considerado en sí mismo como determinante del teologizar" (NOEMI, 1996, p. 31). Con esa perspectiva histórica y de metodología teológica se advierte más claramente lo sucedido en la Conferencia de 1968 que marcará las décadas siguientes: "lo más decisivo de Medellín", argumenta Noemi, no está en haber puesto de relieve el tema de la liberación como tal, "sino en que por primera vez y de manera explícita, conscientemente, se considera la situación de América Latina, no más como un accidente prescindible, sino como antecedente al que queda confrontado el ejercicio teológico. (...) Se motiva a un quehacer y ejercicio teológicos situados y responsables de la realidad concreta y no al margen de la misma." (NOEMI, 1996, p. 46).

En tercer lugar, la perspectiva de una Iglesia fundada "desde abajo", desde la perspectiva de Ad gentes y no desde Lumen gentium, como formula Theobald, hasta cierto punto caracteriza la eclesiología de la Conferencia de Medellín (1968) y su valorización de las pequeñas comunidades. El surgimiento unos años antes del Concilio y sobre todo el desarrollo de las Comunidades Eclesiales de Base, que en buena medida encarnan esa dinámica, es considerado un típico fenómeno del posconcilio latinoamericano (FERRARO; 2015; LUCIANI, 2018). Precisamente el concepto de "eclesiogénesis", que Theobald propone, aunque con un sentido un poco diverso (THEOBALD, 2017, p. 429-461), ha sido forjado en este contexto temático e histórico (BOFF, 1977).

Este "modo de proceder" hizo posible un "proceso de madurez" que colaboró a dar origen a una identidad, en cierto modo nueva, en la historia de la Iglesia: la figura eclesial latinoamericana posconciliar (GUTIÉRREZ, 
1987, p. 214), ${ }^{12}$ que ha tenido en la opción por los pobres su signo más representativo (LUCIANI, 2020). Se trata de la irrupción de los pobres, un "lugar teológico" - topos y kairós - que devino la periferia existencial decisiva para la interpretación del Evangelio.

Naturalmente que esta lectura interpretativa de estas décadas no debe desconocer las ambigüedades en este desarrollo histórico ni opacar que los puntos de renovación solo han alcanzado algunos niveles en la vida de la Iglesia. Pero el sentido de la orientación de una nueva figura emancipadora, liberadora y decolonial está delineado.

\section{Reflexión final}

En síntesis, puede advertirse que (a) la autoconciencia de una Iglesia regional, (b) la consagración de una metodología de trabajo pastoral e investigación teológica que presta primaria atención a la localización (ver-juzgar-actuar) (BRIGHENTI, 2015), al lugar social, incluso con la categoría significativa de lugar teológico (Aquino JUNIOR, 2013; SCHICKENDANTZ, 2016; COSTADOAT, 2017), (c) el nacimiento de una teología contextual, por primera vez con relevancia internacional, como la teología de la liberación, (d) el surgimiento de una de las grandes novedades eclesiales y teológicas de nuestra época, como la opción preferencial por los pobres, comprendida de manera cada vez más plural -incluye variables de género, raza, etc. - en orden a recoger "adecuadamente la pluralidad de los sujetos pobres de América Latina y su 'hibridez' cultural” (MELLA, 2016, p. 456), (e) el reconocimiento de que esta dimensión evangélica de justicia reclama profundas transformaciones políticas, no solo conversiones personales, y que se presenta como una crítica estructural frente a una "violencia institucionalizada" (Medellín) son todas realidades que, a la luz de una enorme mayoría de personas, tienen relación intrínseca con el Vaticano II. Con sus limitaciones el Concilio pertenece, de forma esencial, al discurso emancipador en América Latina y el Caribe. Los mismos autores latinoamericanos que Dussel cita como ejemplos porque, a su juicio, pensaron "con sus propias cabezas" testimonian esta narrativa.

Según este análisis un proyecto intercontinental sobre el Vaticano II en perspectiva de interculturalidad puede servir, por una parte, para la profundización del camino recorrido por las comunidades cristianas en el

\footnotetext{
${ }^{12}$ Es posible verificar procesos análogos vinculados al Vaticano II en otras zonas geográficas de la Iglesia, (OROBATOR, 2012; MATTAM, 2016, p. 504-507). El teólogo norteamericano Roger Haight ha publicado un artículo muy interesante sobre lo él que llama "el nacimiento de la teología estadounidense". Allí se muestra con claridad el carácter providencial y decisivo del Concilio para ese "nacimiento" (HAIGHT, 2019).
} 
continente en estas décadas y, por otra, para estar a la altura de algunos de los más importantes desafíos que demandan procesos de transformación política, luchas en favor de la equidad socio-económica, del reconocimiento de las alteridades negadas y de la decolonialidad cultural.

\section{Siglas}

$$
\begin{aligned}
& \mathrm{AA}=\text { Apostolicam actuositatem }- \text { Vaticano II } \\
& \mathrm{AG}=\text { Ad gentes }- \text { Vaticano II } \\
& \mathrm{CD}=\text { Christus Dominus }- \text { Vaticano II } \\
& \mathrm{DH}=\text { Dignitatis humanae }- \text { Vaticano II } \\
& \mathrm{DV}=\text { Dei Verbum }- \text { Vaticano II } \\
& \mathrm{GS}=\text { Gaudium et spes }- \text { Vaticano II } \\
& \mathrm{LG}=\text { Lumen gentium }- \text { Vaticano II } \\
& \mathrm{OE}=\text { Orientalium ecclesiarum }- \text { Vaticano II } \\
& \mathrm{PC}=\text { Perfectae caritatis }- \text { Vaticano II } \\
& \mathrm{PO}=\text { Presbyterorum ordinis }- \text { Vaticano II } \\
& \mathrm{SC}=\text { Sacrosanctum concilium }- \text { Vaticano II } \\
& \mathrm{UR}=\text { Unitatis redintegratio }- \text { Vaticano II }
\end{aligned}
$$

\section{Referencias}

ALBUQUERQUE, F. das C. de. Decolonialidade e libertação da teologia na América Latina: da libertação a decolonialidade. Perspectiva Teológica, Belo Horizonte, v. 51, n. 3, p. 555-574, Set./Dez. 2019.

AQUINO JUNIOR, F. El carácter social de la teología. Revista Latinoamericana de Teología, San Salvador, n. 90, p. 279-298, Set., 2013.

ARCE-VALENTIN, R. Towards a Decolonial Approach in America Latin Theology. Theology Today, Princeton NJ, v. 74, n. 1 p. 41-48, Abr. 2017.

ARENAS, S.; ARANDA, M. (Eds.) Ecclesiam Dei. Propuesta de Chile en el proceso de elaboración del Documento sobre la Iglesia del Concilio Vaticano II. Santiago: Anales de la Facultad de Teología PUC, 2014.

AZCUY, V. R. La eclesiología inclusiva del Concilio Vaticano II. In: AZCUY, V. R.; CAAMAÑO, J. C.; GALLI, C. M. (Ed.). La Eclesiología del Concilio Vaticano II. Memoria, reforma y profecía. Buenos Aires: Agape, 2015. p. 535-555.

BEOZZO, J. O. A Igreja do Brasil no Concílio Vaticano II 1959-1965. São Paulo: Paulinas, 2005.

BEOZZO, J. O.; LUZ MARQUES, L. C. A Igreja do Brasil na preparação do Vaticano II. Horizonte, Belo Horizonte, v. 9, n. 24, p. 986-1009, Dez. 2011.

BEOZZO, J. O. Vaticano II: 50 años después en América latina y el Caribe. Concilium, Madrid, n. 346, p. 439-445. Jun. 2012. 
BLANCO, J. Cartografía del pensamiento latinoamericano contemporáneo. Una introducción. Guatemala: Universidad Rafael Landívar, 2009.

BOFF, 1. Eclesiognese - as comunidades eclesiais de base reinventam a Igreja. Petrópolis: Vozes, 1977.

BOFF, 1. Theology of Liberation: Creative Acceptance of Vatican II from the Viewpoint of the Poor. In: BOFF, L. When Theology Listens to the Poor. San Francisco: Harper \& Row, 1988. p. 1-31.

BÖTTIGHEIMER, C; DAUSNER, R. (Eds.). Vatikanum 21. Die bleibenden Aufgaben des Zweiten Vatikanischen Konzils im 21. Jahrhundert. Freiburg i.Br.: Herder, 2016.

BRIGHENTI, A. Método ver-julgar-agir. In: DECIO PASSOS, J.; LOPES SANCHEZ, W. (Coord.). Dicionário do Concílio Vaticano II. São Paulo: Paulinas, 2015. p. 608-615

CASTRO-GÓMEZ, S. The Social Sciences, Epistemic Violence, and the Problem of the 'Invention of the Other'. Nepantla: Views from South, Durham NC, v. 3, n. 2, p. 269-285, 2002.

CEPAL, Situación de las personas afrodescendientes en América Latina y desafíos de políticas para la garantía de sus derechos. Santiago: Naciones Unidas, 2017.

CLIFFORD, C; FAGGIOLI, M. (Ed.). Oxford Handbook of Vatican II. Oxford: Oxford University Press, 2021.

CODINA, V. Las Iglesias del continente 50 años después del Vaticano II. In: Congreso Continental de Teología (Ed.). 50 años del Vaticano II. Análisis y perspectivas. Bogotá: Paulinas, 2013. p. 81-92.

CONGRESO CONTINENTAL DE TEOLOGÍA (Ed.). 50 años del Vaticano II. Análisis y perspectivas. Bogotá: Paulinas 2013.

COSTADOAT, J. ¿Hacia un nuevo concepto de revelación? La historia como 'lugar teológico' en la Teología de la liberación. In: AZCUY, V. R.; GARCÍA, D.; SCHICKENDANTZ, C. (Eds.). Lugares e interpelaciones de Dios. Discernir los signos de los tiempos. Santiago: Ediciones Universidad Alberto Hurtado, 2017. p. 105-132.

DUSSEL, E. Epistemological Decolonization of Theology. In: JOSEPH, M. P.; HUANG, P. H.; HSU, V. (Ed.). Wrestling with God in Context. Revisiting the Theology and Social Vision of Shoki Coe. Minneapolis: Augsburg Fortress, 2018. p. 47-63.

ECKHOLT, M. Eine interkontinentale Kommentierung des Zweiten Vatikanischen Konzils. Hermeneutische Fragen und ekklesiologische Herausforderungen. Zeitschrift für Missionswissenschaft und Religionswissenschaft, Sankt Ottilien, n. 104, p. 68-83, 2020.

FAGGIOLI, M; VICINI, A. (Ed.). The Legacy of Vatican II. New York: Paulist Press, 2015.

FAGGIOLI, M. Council Vatican II: Bibliographical Survey 2016-2019. Cristianesimo nella storia, Bologna, n. 40, p. 171-198, Set./Dez. 2019a.

FAGGIOLI, M. Adapting to a 'World Church'. A New International Commentary on Vatican II. 2019b. Disponible en: https://www.commonwealmagazine.org/ adapting-world-church. Acceso: mayo 2020.

FERRARO, B. CEBs - Comunidades eclesiais de base. En: DECIO PASSOS, J.; LOPES SANCHEZ, W. (Coord.). Dicionário do Concílio Vaticano II. São Paulo: Paulinas, 2015. p. 91-95. 
FORNET-BETANCOURT, R. La filosofía intercultural. In: DUSSEL, E.; MENDIETA, E.; BOHORQUEZ, C. (Ed.). El pensamiento filosófico latinoamericano, del Caribe y "latino" (1300-2000). México: Siglo XXI editores, 2009. p. 639-646.

FREIRE, G. et al. Afrodescendientes en Latinoamérica: Hacia un marco de inclusión. Washington, DC.: World Bank, 2018.

FRIGERIO, A. De la "desaparición" de los negros a la "reaparición" de los afrodescendientes: comprendiendo la política de las identidades negras, las clasificaciones raciales y de su estudio en la Argentina. En: CLACSO. Los estudios afroamericanos y africanos en América Latina: herencia, presencia y visiones del otro. Buenos Aires: CLACSO, 2008. p. 117-144.

GAILlARDETZ, R. (Ed.). Cambridge Companion of Vatican II. Cambridge: Cambridge University Press, 2020.

GALLI, C. M. Diálogo teológico con Walter Kasper: La recepción de la eclesiología conciliar en la Argentina. Teología, Buenos Aires, v. 52, n. 118, p. 159-183, Dez. 2015.

GIRARDI, L.; GRILLO, A.; VIGANÒ, D. E. Commentario ai documenti del Vaticano II. 1. Sacrosanctum concilium. Inter mirifica. Bologna: Edizioni Dehoniane, 2014.

GUTIÉRREZ, G. Teología de la liberación. Perspectivas. Lima: CEP, 1971.

GUTIÉRREZ, G. La recepción del Vaticano II en Latinoamérica. In: Alberigo, G.; Jossua, J. (Eds.), La recepción del Vaticano II. Madrid: Cristiandad, 1987. p. 213-237.

GUTIÉRREZ, G. Significado y alcance de Medellín. In: GUTIÉRREZ, G. De Medellín a Aparecida. Artículos reunidos. Lima: CEP, 2018. p. 65-122.

HAIGHT, R. The Birth of American Catholic Theology. Theological Studies, Thousand Oaks CA, v. 80, n. 1, p. 7-36, Fev. 2019.

HÜNERMANN, P.; HILBERATH, B. J. (Ed.). Herders Theologischer Kommentar zum Zweiten Vatikanischen Konzil. Freiburg i.B.: Herder, 2004-2005.

KOCHUTHARA, S. G. (Ed.). Revisiting Vatican II. 50 Years of Renewal. Bangalore: Dharmaram Publications, 2014-2015.

LAMBERIGTS, M. et al. (Ed.). 50 años después del Vaticano II. Teólogos del mundo entero deliberan. Paris: Federatio Internationalis Universitatum Catholicarum, 2015.

LANDER, E. (ed.). La colonialidad del saber: eurocentrismo y ciencias sociales: perspectivas latinoamericanas. Buenos Aires: CLACSO, 2000

LECHINI, G. Los estudios sobre África y Afroamérica en América Latina. El estado del arte. In: CLACSO. Los estudios afroamericanos y africanos en América Latina: herencia, presencia y visiones del otro. Buenos Aires, 2008. p. 11-32.

LIBANIO, J. B. A trinta anos do encerramento do Concílio Vaticano II. Chaves teológicas de leitura. Perspectiva teológica, Belo Horizonte, v. 27, n. 73, p. 297-332, Set./Dez. 1995.

LIBERTI, L. La participación de los obispos argentinos en los esquemas del Vaticano II. Buenos Aires: Editorial Guadalupe, 2017. 3 vol.

LUCIANI, R. Medellín como acontecimiento sinodal. Una eclesialidad colegiada fecundada y completada. Horizonte, Belo Horizonte, v. 16, n. 50, p. 482-516, Mai./ Ago. 2018. 
LUCIANI, R. Francis and the Pastoral Geopolitics of Peoples and Their Cultures: A Structural Option for the Poor. Theological Studies, Thousand Oaks CA, v. 81, n. 1, p. 181-202, Mar. 2020.

MATTAM, J. Catholic Christianity in India. Asian Horizons, Bangalore, v. 10, n. 3, p. 490-508, Set. 2016.

MELLA, P. La teología latinoamericana y el giro descolonizador. Perspectiva Teológica, Belo Horizonte, v. 48, n. 3, p. 439-452. Set./Dez. 2016.

MESTERS, C.; OROFINO, F. Leitura popular da Bíblia. In: PASSOS, J. D.; LOPES SANCHEZ, W. (Coord.). Dicionário do Concílio Vaticano II. São Paulo: Paulinas, 2015. p. 533-536.

MIGNOLO, W. El pensamiento decolonial: desprendimiento y apertura. In: CASTRO-GÓMEZ, S.; GROSFOGUEL, R. (Eds.). El giro decolonial: reflexiones para una diversidad epistémica más allá del capitalismo global. Bogotá: Siglo del Hombre Editores, 2007. p. 25-46.

NOEMI, J. Rasgos de una teología latinoamericana. In: MENDES DE ALMEIDA, L. et al. El futuro de la reflexión teológica en América Latina. Bogotá: CELAM, 1996. p. 29-74.

NOEMI, J. Rasgos, imperativos y desafíos. In: Noemi, j.; Castillo, F. Teología latinoamericana. Santiago: Centro Ecuménico Diego de Medellín, 1998. p. 9-93.

OROBATOR, A. Mirada retrospectiva al futuro. Impulsos transformativos del concilio Vaticano II para el catolicismo africano. Concilium, Madrid, n. 346, p. 421-427, 2012.

PASSOS, J. D.; LOPES SANCHEZ, W. (Coord.). Dicionário do Concílio Vaticano II. São Paulo: Paulinas, 2015.

RAHNER, K. Theologische Grundinterpretation des II. Vatikanischen Konzils. In: RAHNER, K. Schriften zur Theologie. Band 14. In Sorge um die Kirche. Einsiedeln: Benziger Verlag, 1980. p. 287-302.

RICHARD, P. Interpretación latinoamericana de la Biblia. Realidad, método, prospectiva. In: Levoratti, A (Dir.). Comentario Bíblico Latinoamericano. Nuevo Testamento. Estella: Editorial Verbo Divino, 2007. p. 11-18.

SILVA, M. R. da. Teologia Afro (ou Negra) da Libertação: balanço e perspectivas. Horizonte, Belo Horizonte, n. 32, p. 1769-1776, Out./Dez. 2013.

ROUTHIER, G. Vatican II. Relevance and Future. Theological Studies, Thousand Oaks CA, v. 74, n. 3, p. 546-554, Set. 2013.

RUSH, O. The Vision of Vatican II. Its Fundamental Principles. Collegeville, MN: Liturgical Press, 2019.

RUSH, O. Conciliar Hermeneutics. In: GAILLARDETZ, R. (Ed.). Cambridge Companion of Vatican II. Cambridge: Cambridge University Press, 2020. p. 94-112.

SCHICKENDANTZ, C. Un cambio en la ratio fidei. Asociación (aparentemente ilícita) entre principios teológicos y datos empíricos. Teología y Vida, Santiago, v. 57, n. 2, p. 157-184, 2016.

SCHICKENDANTZ, C. Un enfoque empírico-teológico. En el método, el secreto de Medellín. Teología y Vida, Santiago, v. 58, n. 4, p. 421-445, 2017. 
SCHICKENDANTZ, C. ¿Una exaltación de lo empírico? La metodología teológico-pastoral de Medellín en debate. Horizonte, Belo Horizonte, v. 16, n. 50, p. 517-543, Mai./Ago. 2018a.

SCHICKENDANTZ, C. Signos de los tiempos. Sentido y vigencia de una forma de proceder teológicamente. Albertus Magnus, Bogotá, v. 9, n.2, p. 85-104, jul. 2018b.

SUESS, P. Prolegómenos sobre descolonización y colonialidad de la teología en la Iglesia desde una perspectiva latinoamericana. Concilium, Madrid, n. 350, p. 85-96, Abr. 2013.

SUSIN, L. América Latina, la tierra multicolor. La diversidad cultural y religiosa en América Latina. Concilium, Madrid, n. 354, p. 73-85, 2001.

THEOBALD, C. La réception du concile Vatican II. 1. Accéder à la source. Paris: Cerf, 2009.

THEOBALD, C. Le concile Vatican II. Quel avenir? Paris: Cerf, 2015a.

THEOBALD, C. The Principle of Pastorality at Vatican II. In: FAGGIOLI, M.; VICINI, A. (Eds.). The Legacy of Vatican II. New York: Paulist Press, 2015b, p. 26-37.

THEOBALD, C. Rezeption und Zukunftspotentiale des Zweiten Vatikanischen Konzils. In: BÖTTIGHEIMER, C; DAUSNER, R. (Eds.). Vatikanum 21. Die bleibenden Aufgaben des Zweiten Vatikanischen Konzils im 21. Jahrhundert. Freiburg i.Br.: Herder, 2016. p. 38-44.

THEOBALD, C. Urgences pastorales. Montrouge: Bayard Editions, 2017.

THEOBALD, C. La osadía de anticipar el futuro de la Iglesia. Concilium, Madrid, n. 377, p. 459-469. 2018a.

THEOBALD, C. Christentum als Stil. Für ein zeitgemäßes Glaubensverständnis in Europa. Freiburg i.Br.: Herder, 2018b.

TOMICHÁ, R. Teologías de la liberación indígenas. Balance y perspectivas. Horizonte, Belo Horizonte, v. 11, n. 32, p. 1777-1800, Dez. 2013.

VENEGAS, C.; MORENO, E. Conversaciones con Ronaldo Muñoz. Santiago: Fundación Coudrín, 2010.

VILLAR, J. (Dir.). Diccionario Teológico del Concilio Vaticano II. Pamplona: EUNSA, 2015.

Artículo sometido en 29.06.2020 y aprobado en 30.10.2020.

Carlos Schickendantz es Doctor en Teología (Eberhard-Karls-Universität Tübingen, Alemania). Profesor e investigador en el Centro Teológico Manuel Larraín, Universidad Alberto Hurtado, Santiago, Chile. Orcid: 0000-0003-3897-804X. E-mail: carlosschickendantz@gmail.com

Dirección: Alameda 1869

Santiago - Chile 